\title{
Extent of adoption of the recommended Sweet Pepper production technology by the Sweet Pepper producers
}

\author{
*Mr. Tushar Panigrahi ** Dr. Y. K. Singh *** Dr. Sandhya Choudhary \\ * Ph.D.Research Scholar, Mahatma Gandhi Chitrakoot Gramoday University Chitrakoot (MGCGV) Satna \\ Madhya Pradesh India \\ ** Professor Department of Agriculture Extension, Mahatma Gandhi Chitrakoot Gramoday \\ University, Chitrakoot (MGCGV) Satna Madhya Pradesh India. \\ *** Associate Professor Extension Education, College of Agriculture, Indore
}

\begin{abstract}
Sweet Pepper/Bell Pepper (Capsicum annum) is one of the most favored species of chilli and widely used universal spice, named as wonder spice. Different varieties of it are cultivated for varied uses like vegetable, pickles, spice and condiments. Sweet pepper, the gifted plant of nature is generally regarded as the king of cultivated crops has 80 per cent consumption in food purpose and others is using in industry. In india, the farmers grow hybrid sweet pepper and deshi sweet pepper. At present an area of 98 thousand hectare is occupied by hybrid sweet pepper, which constitutes 86 per cent of total sweet pepper area. India contributes 17.9 per cent of the total production. Out of total pesticide usage, Sweet pepper crop alone consumes 2.6 per cent. Adoption pattern of the recommended cultivation practices of the sweet pepper growers. The Study has been conducted in Raipur district of Chhattisgarh Out of thirteen blocks the TILDA block has been selected randomly with 750 respondents. For the study of adoption behavior nineteen recommended practices of Sweet Pepper production technology were selected and found complete adoption in maximum practices.

Key Words- Sweet Pepper, Adoption Behavior
\end{abstract}

\section{Introduction}

Sweet Pepper/Bell Pepper (Capsicum annum) is one of the most favored species of chilli and widely used universal spice, named as wonder spice. Different varieties of it are cultivated for varied uses like vegetable, pickles, spice and condiments. Sweet pepper, the gifted plant of nature is generally regarded as the king of cultivated crops has 80 per cent consumption in food purpose and others is using in industry. India has the largest area under sweet pepper with an average productivity of 13.2 tones / ha (APEDA 2010). However its production and yield are much lower as compared to those of the major sweet pepper growing countries of the world. In India, the farmers grow hybrid sweet pepper and deshi sweet pepper. At present an area of 98 thousand hectare is occupied by hybrid sweet pepper, which constitutes 86 per cent of total sweet pepper area. India contributes 17.9 per cent of the total production. Out of total pesticide usage, Sweet pepper crop alone consumes 2.6 per cent. Though, the Chhattisgarh is the major sweet pepper producing state in India, it's know main yielder state of sweet pepper but the average yield of sweet pepper is very poor because of non-adoption of the improved production technology. There exists tremendous scope to increase the sweet peeper yield provided the acceptance and implementation of recommended cultivation practices. With this background, the study is planned to underlying objectives know the extension participation of sweet pepper growers, adoption pattern of the recommended cultivation practices of the sweet pepper growers, to find out the reasons for no adoption or over adoption or partial adoption of recommended cultivation practices, and finally the constraints faced in cultivation of sweet pepper. Sharshar et al. (1998) in their study level of farmer's knowledge and implementation levels of technology for Sweet Pepper crop on reclaimed lands indicated low knowledge and implementation levels regarding new technical practices for Sweet Pepper crops. Farmers ranked field visits and demonstration visit as the most useful extension tools.

Sriram and Annamalai (2002) studied the effectiveness of different extension education strategies for converting non-Sweet Pepper growers into Sweet Pepper growers in Tamil Nadu, India. A sample of 72 nonSweet Pepper growers from three taluks in Salem district were selected for the study. Three treatments, viz. lecture +field visit + discussion forum $\left(\mathrm{T}_{1}\right)$, lecture assisted with slide show + demonstration +discussion forum $\left(\mathrm{T}_{2}\right)$, and lecture + video+ discussion forum $\left(\mathrm{T}_{3}\right)$, were developed and executed to assess respondents' knowledge gain and symbolic adoption behavior. It was found that $T_{1}$ and $T_{2}$ were effective among all the non-Sweet Pepper growers in terms of knowledge gain and symbolic adoption behavior in Sweet Pepper cultivation. Bhople, et al. (2001) on the basis of finding of the present study concluded that the Sweet Pepper growers possessed low level of knowledge about bio-control practices for pest management in Sweet Pepper crop. It is suggested that the extension workers of the state department of agriculture through their regular contacts with the farmers should try to provide detail information about bio control practices for pest management in Sweet 
Pepper to the farmers. This will help in creating awareness and equipping the Sweet Pepper growers about the information on bio-control technology.

\section{Significance of the study.}

The introduction of new farm technology initiated the transformation of Indian agriculture and thereby created a large potential for increasing agricultural production. Agricultural production depends on the extent to which farmer adopt new agricultural innovations. It is felt that large parts of gains from new farm technology still remain to be realized. This is because of non-adoption of new innovations on the farm, since the adoption process is not simple and a number of social, economic, psychological factors influence it to a considerable extent. state in India but the average yield of Sweet Pepper is very poor because the farmers are not adopting the improved Sweet Pepper production technology. (socio-techno-economic \& psychological) on the adoption of Sweet Pepper production technology, which will help the planners, policy makers, scientists and extension workers in understanding and devising appropriate measures to tackle the problems more efficiently. Though, the Chhattisgarh is the major Sweet Pepper producing state in India but the average yield of Sweet Pepper is very poor because the farmers are not adopting the improved Sweet Pepper production technology. Therefore, it is necessary to investigate the influence of various factors (socio-techno-economic \& psychological) on the adoption of Sweet Pepper production technology, which will help the planners, policy makers, scientists and extension workers in understanding and devising appropriate measures to tackle the problems more efficiently.

\section{Objective-}

To determine the extent of adoption of the recommended Sweet Pepper production technology by the Sweet Pepper producers.

\section{Material \& Method}

The Study has been conducted in Raipur district of Chhattisgarh Out of thirteen blocks the TILDA block has been selected randomly. The block has the maximum area 8864 (9.40\%) under Sweet Pepper crop. TILDA block has 9 RAEO circles out of which 10 villages had been selected randomly. The list of Sweet Pepper producers village-wise of the above selected villages was prepared and 10 farmers from each village were selected by random sampling method. Thus, the total sample consisted of 100 Sweet Pepper producers spread over 10 villages in the selected TILDA block. Data were collected with the help of pre-tested interview schedule, personally. The collected data was classified and tabulated and interpretations were made with the help of statistical tool.

\section{Extent of adoption:}

\section{Result \& Discussion}

For the study of adoption behavior nineteen recommended practices of Sweet Pepper production technology viz, field preparation, improved varieties, time of sowing, seed rate, seed treatment of fungicides, seed treatment of culture, recommended row to row spacing, deep sowing, recommended dose of chemical fertilizers, use of bio-fertilizers, irrigation management, weed identification, method of weed control, weedicides insect control, disease control, Integrated Pest Management (IPM), and Integrated Disease Management (IDM), were selected. The weight age of 2 for complete adoption, 1 for partial adoption of each practice was assigned. The total score obtained by the respondent from all the nineteen practices was the adoption score of individual respondent. Finally this adoption score obtained by individual respondent was converted into adoption index.

Table - Distribution of respondents according to their level of $\mathrm{N}=\mathbf{7 5 0}$

\begin{tabular}{|l|l|l|}
\hline \multirow{2}{*}{ Adoption } & \multicolumn{2}{|c|}{ Sweet Producer } \\
\cline { 2 - 3 } & No. of Respondents & Mean Score \\
\hline Complete Adoption & $42 \%$ & 15.49 \\
\hline Partial Adoption & $58 \%$ & 16.49 \\
\hline Total & 100 & 32.98 \\
\hline
\end{tabular}

The data in above table show that out of the total 100 Sweet Pepper producers, 42 per cent had complete adoption, while 58 per cent had partial adoption. The mean of the complete adoption category was found to be 15.49 while that of the partial adoption category were 16.49 . The overall mean was 32.98 . Thus, it can be 
concluded that majority of the Sweet Pepper growers had partial adoption. Hence, from the on-going discussion it can be concluded that majority of the respondents belonged to educated category having high socio-economic status, high attitude toward improved farm practices, high mass media exposure, high cosmopoliteness, high risk preference, high innovativeness, high economic motivation and high management orientation and high knowledge in case of Sweet Pepper crops. It was also found that majority of the Sweet Pepper growers were in young category of age group, small size of land holding, no social participation, seldom extension participation, low information seeking behavior, low exposure to demonstration, low exposure to training and low adoption.

\section{Extent Of Adoption Of The Recommended Sweet Pepper Production Technology By The Sweet Pepper Producers}

Table- Adoption behavior of Sweet Pepper growers regarding recommended Sweet Pepper production technology.

\begin{tabular}{|l|l|l|l|}
\hline S.No. & Name of practices & Adoption percentage \\
\cline { 3 - 4 } & & $\begin{array}{l}\text { Complete } \\
\text { Adoption }\end{array}$ & $\begin{array}{l}\text { Partial } \\
\text { Adoption }\end{array}$ \\
\hline 1 & & 71 & 29 \\
\hline 2. & Field preparation & 48 & 52 \\
\hline 3. & Improved varieties & 76 & 24 \\
\hline 4. & Time of sowing & 69 & 31 \\
\hline 5. & Seed rate & 32 & 68 \\
\hline 6. & Seed treatment with fungicides & 76 \\
\hline 7. & Seed treatment of culture & 24 & 27 \\
\hline 8. & Method of sowing & 58 \\
\hline 9. & Recommended row to row spacing & 73 & 75 \\
\hline 10. & Deep sowing & 42 & 79 \\
\hline 11. & Recommended dose of chemical fertilizers & 25 & 72 \\
\hline 12. & Use of bio-fertilizer & 21 & 53 \\
\hline 13. & Irrigation management & 28 & 63 \\
\hline 14. & Weed identification & 47 & 51 \\
\hline 15. & Method of weed control & 37 & 80 \\
\hline 16. & Weedicides & 49 & 33 \\
\hline 17. & Insect control & 20 & 66 \\
\hline 18. & Disease control & 67 & 73 \\
\hline 19. & Integrated pest management (IPM) & 44 & 85 \\
\hline
\end{tabular}

Regarding the adoption behavior of the Sweet Pepper growers about recommended Sweet Pepper production technology, complete adoption was found in the majority of the respondents in case of field preparation, time of sowing, seed rate, method of sowing, insect control, whereas, partial adoption was found in the majority of the respondents in case of practices like improved varieties, seed treatment with fungicides, seed treatment with culture, recommended row to row spacing, deep sowing, recommended dose of chemical fertilizers, use of bio- fertilizers, irrigation management, weedicides, method of weed control, disease control, integrated pest management (IPM) and integrated disease management (IDM).

\section{Implication-}

Sweet Pepper producers are not able to adopt the recommended practices in full due agro-climatic constraints, moisture stress during crop growth period, occurrence of insect pests \& diseases, less fertility of soil, crop damage due to heavy rains during maturity period. Technological constraints such as lack of knowledge about I P M \& I D M., lack of knowledge of bio-agent, poor seed germination due to low soil moisture at the time of sowing, improper use of insecticides, imbalanced used of fertilizer, lack of knowledge proper use of weedicides, lack of knowledge of scientific crop production. Infrastructure constraints such as lack of irrigation facilities. Inability to purchase modern agriculture implements, inability to purchase fertilizers and plant protection chemicals unavailability H Y V seed at the time of sowing. Economic constraints such as nonavailability of credit facilities, high cost of chemical fertilizers, low price of Sweet Pepper, interference of middle man in marketing, high cost of cultivation, high cost of pesticides \& weedicides. These constraints need to be highlighted and dealt with by the concerned authorities and departments so that the problems could be solved.

\section{Reference}

[1]. Bhople, R.S., Shinde, P.S. and S.S. Dhule, (2001). Knowledge and adoption Bio - control Pest Management in Sweet Pepper. Maha. J. of Extn. Edun. XX (18-21)

[2]. Sharshar, H.A. and Mansour, M.A. and S.A. Shady, (1998). Farmers knowledge and implementation levels concerning new technical practices of Sweet Pepper crops, and proper extension methods in reclaimed lands of kafr EI-Sheikh govern orate. Alexandria journal of agri. Research. 43 (3): 1-26. 
[3]. Sriram, N. and R. Annamalai, (2001). Extension education strategies orconverting non-Sweet Pepper growers into Sweet Pepper growers in Tamil Nadu. Madras Agri. ournal, 88 (10-12): 596-602

[4]. Yaldz, G.; Ozguven, M. (2011). Adaptation of different ornamental pepper ( Capsicum Sp. Webster, L. R.; Peppin, J. F.; Murphy, F. T.; Lu, B.; Tobias, J. K.; Vanhove, G. F. (2011). Efficacy, safety, and tolerability of NGX-4010, capsaicin 8\% patch, in an open-label study of patients with peripheral neuropathic pain. Diabetes Research and Clinical Practice 93(2): 187-197

[5]. Wetwitayaklung, P.; Phaechamud, T.; Penpun, W.; Thawatchai, P. (2011). Antioxidant activities and phenolic content of Solamun and Capsicum sp. Research Journal of Pharmaceutical, Biological and Chemical Sciences 2(2): 146-154.) species and lines in Cukurova conditions. Yuzuncu Yil Universitesi Journal of Agricultural Sciences 21(1): 1-11. 